\title{
Processos metonímicos no movimento FemVertising sob enfoque crítico e multimodal
}

\author{
Edna Clara Januário de ARAÚJO (D \\ Universidade de São Paulo (USP)
}

RESUMO

Considerando a mudança de posicionamento no campo publicitário diante das novas demandas sociais, este trabalho busca examinar, na materialidade linguageira e nos aspectos imagéticos, de que forma as escolhas linguísticas e visuais de três peças publicitárias de produtos de beleza veiculadas pelas marcas quem disse berenice?, Avon e Dove nos permitem identificar as ideologias subjacentes às publicidades e sua relação com os inte-

\section{ఠ}

OPEN ACCESS

EDITADO POR

- Raquel Freitag (UFS)

AVALIADO POR

- Maria da Graça dos S. Faria (UFMA)

- Aline Aver Vanin (UFCSPA)

DATAS

- Recebido: 13/08/2021

- Aceito: 20/12/2021

- Publicado: 22/12/2021

COMO CITAR

Araújo, E. C. J. (2021). Processos

metonímicos no movimento Femvertising sob enfoque crítico e multimodal. Revista da Abralin, v. 20, n. 2, p. 1-15, 2021. resses mercadológicos das marcas. Consideramos que essas peças publicitárias compõem o movimento FemVertising e, para analisá-las, contamos com as contribuições da Gramática Sistêmico-Funcional, da Gramática do Design Visual e a Multimodalidade, além dos princípios teóricos da Análise Crítica do Discurso. A partir do exame dos textos, observou-se que as marcas modulam os textos multimodais de suas peças publicitárias a fim de convencer o público-alvo de seu posicionamento engajado e comprometido com as atuais demandas sociais relativas à representação da mulher. Este trabalho busca apresentar uma reflexão acerca do posicionamento da publicidade diante do ressurgimento de movimentos contestatórios de cunho feminista, lançando luz sobre o estudo das estratégias persuasivas na publicidade contemporânea, evidenciando seus modos de orientar e reforçar determinados pontos de vista de acordo com seus objetivos mercadológicos.

\section{ABSTRACT}

Considering the change in stance in the advertising field in the face of new social demands, this paper seeks to examine, in the materiality of language 


\section{REVISTA DA ABRALIN}

and imagery, how the linguistic and visual choices of three pieces of advertising of beauty products run by brands quem dissse berenice?, Avon and Dove allow us to identify the ideologies underlying advertising and its relationship with the marketing interests of brands. We consider that these advertising pieces make up the FemVertising movement and, to analyze them, we made use of contributions from Systemic-Functional Grammar, Visual Design Grammar and Multimodality, in addition to the theoretical principles of Critical Discourse Analysis. After analysing the texts, it was observed that brands modulate the multimodal texts of their advertising pieces in order to convince the target audience that their position is engaged in and committed to current social demands related to the representation of women. This paper seeks to present a reflection on the stance of advertising in the face of the resurgence of feminist protest movements. We also aim to shed light on the study of persuasive strategies in contemporary advertising, highlighting its ways of guiding and reinforcing certain points of view in accordance with its marketing objectives.

\section{PALAVRAS-CHAVE}

FemVertising. Multimodalidade. Análise Crítica do Discurso.

\section{KEYWORDS}

FemVertising. Multimodality. Critical Discourse Analysis.

\section{Introdução}

Nos últimos anos, a publicidade, influenciada por uma mudança no cenário midiático no que diz respeito ao tratamento dos grupos minoritários, passou a mudar seu posicionamento diante das novas demandas sociais. Com isso em mente, este trabalho visa investigar de que forma diferentes marcas de cosméticos incorporaram tais mudanças à parte de suas campanhas a fim de se beneficiar comercialmente. Pretende-se analisar, assim, de que maneira as marcas quem disse berenice?, Avon e Dove compõem processos metonímicos, isto é, constroem significados a partir da noção metonímica de "uma coisa tomada por outra" (FENG, 2017) em determinadas peças publicitárias a fim de convencer o público-alvo de que suas ideias estão ligadas a questões relativas ao empoderamento feminino. É importante considerarmos que, anteriormente, as publicidades relacionadas a produtos de beleza apresentavam uma imagem padronizada da mulher, representando-a de acordo com o padrão estético comumente aceito pela sociedade. Em contraposição a esse modelo, as peças em questão apresentam diferentes representações femininas, como discutiremos mais adiante. 


\section{REVISTA DA ABRALIN}

Em decorrência da quarta onda do feminismo, estabelecida a partir de 2012, a luta feminista foi fortalecida e redefinida junto à internet, tornando-se um instrumento de mercado para empresas e artistas que fazem uso de seu discurso à vista de interesses mercadológicos. O discurso feminista foi transformado, assim, em um produto vendável (AZEVEDO, 2017). Consideramos que as peças a serem analisadas são exemplares do movimento de reposicionamento das marcas denominado FemVertising - uma mistura de feminism (feminismo) e advertising (publicidade) -, em que os anúncios publicitários apresentam discursos de empoderamento da mulher tendo em vista seus interesses mercadológicos. Cabe notar que a própria expressão "empoderamento" tem sido frequentemente utilizada meramente para fins comerciais, e não mais como uma noção de emancipação.

Diante disso, nosso principal objetivo é examinar, na materialidade linguageira e nos aspectos imagéticos, de que forma as escolhas linguísticas e visuais nos permitem identificar as ideologias subjacentes às peças publicitárias e sua relação com os interesses mercadológicos das marcas. Para tanto, nossa análise lança o olhar para os processos metonímicos referentes à forma pela qual as mulheres são representadas nas peças publicitárias em questão, que pretendem criar uma imagem "feminista" das marcas. Partimos do pressuposto de que as peças tentam estruturar os elementos verbo-visuais de maneira a projetar diferentes imagens do feminino, a fim de alcançar a adesão de um público de mulheres maior e diversificado.

A fim de verificarmos nossa hipótese, contaremos com a contribuição da Gramática SistêmicoFuncional proposta por Halliday (1994) e Halliday e Matthiessen (2004), com o aparato teórico-metodológico da Gramática do Design Visual e a Multimodalidade conforme Kress e van Leeuwen (2006), com as reflexões acerca dos processos metonímicos segundo Feng (2017), e com os princípios teóricos da Análise Crítica do Discurso (ACD) de Norman Fairclough (2001).

\section{Questões teórico-metodológicas}

Este estudo se insere no campo de saberes da Análise Crítica do Discurso (ACD) que, segundo Fairclough (2001, p. 19), pode ser tomada como "uma abordagem de análise linguística [...] que será útil particularmente para investigar a mudança na linguagem e que será útil em estudos de mudança social e cultural".

Fairclough (2001) propõe uma análise do discurso que seja centrada em um quadro composto por três dimensões: texto (vocabulário, gramática, coesão e estrutura textual), prática discursiva (tipos de atos de fala, coerência textual e intertextualidade/interdiscursividade) e prática social (ideologia e hegemonia). Ao utilizar o termo "discurso", o autor propõe que se considere o uso da linguagem como uma forma de prática social, o que implicaria o discurso como um modo das pessoas agirem sobre o mundo e sobre os outros.

O estudo do corpus da pesquisa será realizado em dois níveis (micro e macroanálise), conforme propõe Fairclough (2001). A análise partirá dos elementos linguísticos, passará pelos elementos visuais e as categorias multimodais, até alcançar as estratégias de persuasão e os aspectos ideológicos 


\section{REVISTA DA ABRALIN}

veiculados pelas marcas de cosméticos em questão. No que diz respeito ao aparato teórico-metodológico em que se baseia a ACD, focaremos em uma de suas abordagens que busca fundamentação na visão sócio-semiótica da Linguística Sistêmico-Funcional de Halliday (1994), como discutiremos a seguir.

\subsection{A Gramática Sistêmico-Funcional}

A Gramática Sistêmico-Funcional (GSF), desenvolvida por Halliday (1994), é uma gramática voltada para o estudo do texto, termo usado pelo autor para se referir a qualquer instância da linguagem. Halliday (1994) busca focalizar, em seu estudo, a produção de significados, e não apenas fazer uma análise estrutural tradicional. O significado, para ele, estaria nos padrões sistêmicos de escolha, sendo produzido por meio da linguagem. Dessa forma, o texto seria, então, o resultado de uma série de escolhas que vão sendo realizadas dentro de uma cadeia de sistemas.

Para a GSF, segundo Halliday e Matthiessen (2004), a construção de significados se dá a partir da elaboração das chamadas metafunções, que correspondem a três linhas de significados: textual, interpessoal e ideacional.

Na Metafunção Ideacional, a oração é estruturada de forma a representar as experiências dos indivíduos. Isso ocorre por meio do sistema de Transitividade, que corresponde aos processos, participantes e circunstâncias da oração. Os participantes variam de acordo com seis processos: material, comportamental, mental, existencial, relacional e verbal (HALLIDAY; MATTHIESSEN, 2004).

Na Metafunção Interpessoal, a oração é organizada na forma de interação entre falante e ouvinte. Essa interação pode ser feita a partir de uma oferta ou um pedido - seja de informações, serviços ou troca de bens - dentro do sistema de Modo, que nos permite identificar se a oração é declarativa, interrogativa ou imperativa (HALLIDAY; MATTHIESSEN, 2004).

Já na Metafunção Textual, a oração é dividida em duas partes: tema e rema. A primeira parte da oração seria o tema, que corresponde ao ponto de partida da mensagem, enquanto o restante, ou seja, a parte em que o tema é desenvolvido, seria o rema. Isso se dá a partir do sistema Temático, que possibilita a organização da oração de acordo com o propósito do falante (HALLIDAY; MATTHIESSEN, 2004).

De acordo com Soares (2017, p. 577), toda escolha linguística realiza as três metafunções ao mesmo tempo, ou seja, "tudo que expressamos linguisticamente contém, simultaneamente, uma informação (Ideacional), dita a alguém (Interpessoal), de algum modo (Textual)". 


\section{REVISTA DA ABRALIN}

\subsection{A Gramática do Design Visual e a Multimodalidade}

A Gramática do Design Visual (GDV) proposta por Kress e Van Leeuwen (2006), se trata de uma expansão da Gramática Sistêmico-Funcional (GSF) de Halliday (1994). Os autores demonstram que as metafunções propostas por Halliday podem ser aplicadas a outros sistemas semióticos, e não somente à linguagem verbal.

Do ponto de vista da Semiótica Social, o texto é encarado como multimodal e, desse modo, as três metafunções propostas por Halliday (1994) podem ser utilizadas para a análise de imagens sob os pressupostos teórico-metodológicos da Gramática do Design Visual.

Sob a perspectiva do aspecto ideacional, Kress e Van Leeuwen (2006) elencam cinco processos principais a partir da análise de imagens, sendo eles: analítico, narrativo, simbólico, reacional e de ação. Do ponto de vista do aspecto interpessoal, os autores classificam as imagens a partir de três dimensões: olhar, enquadramento e perspectiva. Já o aspecto composicional se volta para a composição espacial da imagem, que se apresenta a partir de três categorias: o valor da informação (dado/novo, ideal/real, centro/margem), a saliência e a moldura.

\subsection{Os processos metonímicos}

Um dos elementos que pode ser observado não somente em textos verbais, mas também imagéticos, é a metonímia, que aparece em diferentes contextos. De acordo com Feng (2017), os estudos relacionados à multimodalidade textual têm voltado seu olhar às manifestações não verbais das metonímias. Em seu trabalho, o autor propõe modelar a realização visual de metonímias baseadas na teoria semiótica social de Halliday (1994) e na gramática visual de Kress e Van Leeuwen (2006).

Segundo Feng (2017), assim como as metáforas, as metonímias envolvem o entendimento de "uma coisa tomada por outra". Entretanto, diferentemente das metáforas que relacionam dois domínios conceituais distintos, nas metonímias, a conexão entre as duas partes está dentro de um mesmo campo.

Feng (2017) afirma que é possível estendermos o recurso das palavras aos recursos visuais (expressões faciais, aparência dos personagens etc.). Desse modo, poderíamos apreender a metonímia presente nas imagens considerando seu significado. O autor aborda diferentes perspectivas metonímicas, tais como a referencial, que diz respeito à representação visual parcial da realidade, e a conceitual, que mostra como um significado representacional invoca um significado atitudinal. Para que se possa mapear os diferentes tipos de metonímias presentes nas representações visuais, Feng (2017) apresenta quatro processos metonímicos: acional, analítico, classificatório e reacional. Portanto, considerando que as escolhas composicionais de um texto multimodal não são arbitrárias, é importante analisarmos seus processos metonímicos para que possamos compreender seus significados. 


\section{Análise das peças publicitárias: resultados e discussões}

As três peças publicitárias fazem parte de campanhas veiculadas pelas marcas quem disse berenice? (2015), Avon (2016) e Dove (2016). A escolha do corpus se deu a partir da seleção de publicidades que, ao divulgar produtos de beleza, associasse-os às imagens de mulheres representadas de maneiras diferentes dos padrões estéticos e/ou comportamentais estipulados em períodos passados. Passemos, então, à análise das peças.

\subsection{Peça publicitária da marca quem disse berenice?}

A peça publicitária foi lançada após a marca promover uma campanha em que diferentes mulheres foram fotografadas com placas que diziam que ser ou fazer algo que normalmente não é associado ao gênero feminino "não é pra mim". De acordo com suas histórias, as mulheres seguravam cartazes com frases como "Futebol não é pra mim", "Ser bombeira não é pra mim", "Liderar não é pra mim", sendo que o termo "não" aparecia sempre riscado de vermelho, para que as frases se transformassem em "[...] é pra mim".

Seguindo esse modelo, a campanha referente aos produtos cosméticos foi desenvolvida a partir da ideia de que qualquer produto que uma mulher deseje usar, "é pra ela". Na descrição do vídeo publicitário $^{1}$ veiculado na plataforma YouTube aparecem os seguintes dizeres: "a vida das mulheres tem 'não' demais. a quem disse, berenice? quer te ajudar a se libertar deles pra encontrar o seu jeito de se sentir mais bonita. o primeiro passo pra liberdade começa agora!". Com isso, a marca indica seu desejo de "libertar" e aumentar a autoestima das mulheres, o que poderia ser conquistado a partir do consumo de seus produtos. Passemos, então, à análise da peça publicitária:

\footnotetext{
${ }^{1}$ Disponível em: https://www.youtube.com/watch?v=4XbFv9C_GiY. Acesso em: 10/08/2021.
} 


\section{REVISTA DA ABRALIN}

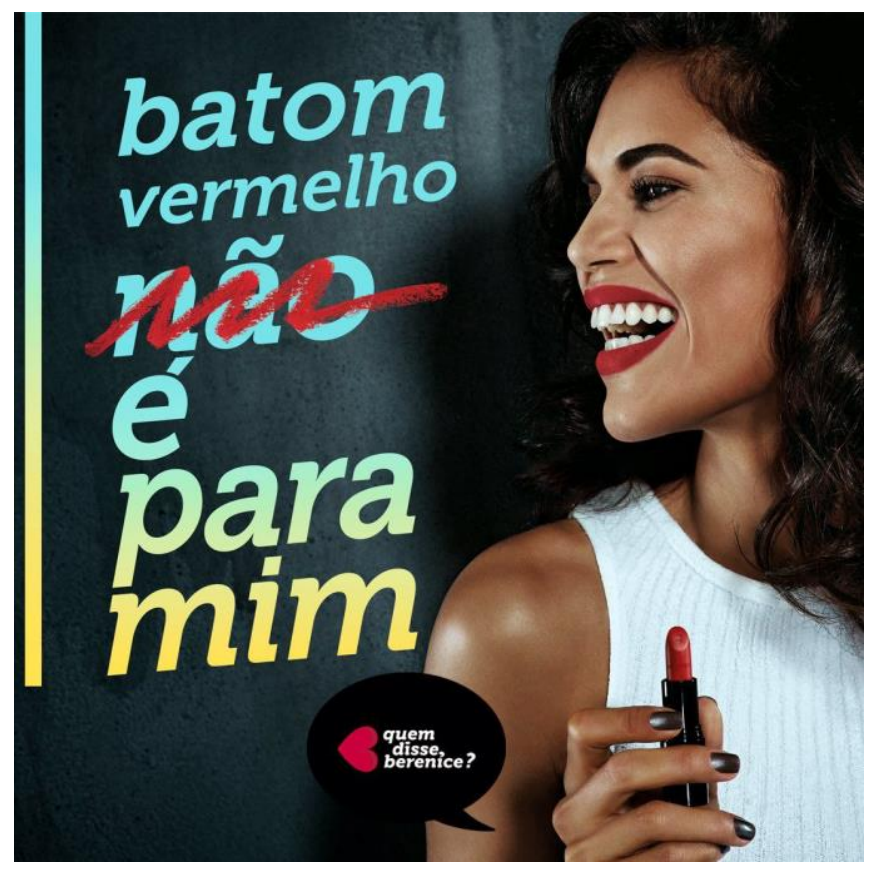

FIGURA 1 - Peça publicitária da marca quem disse berenice?

Fonte: Veiculado pela página de Facebook da marca²

Em conformidade com os pressupostos da GSF, buscamos analisar a peça a partir das três metafunções propostas por Halliday (1994) e Halliday e Matthiessen (2004):

\begin{tabular}{|c|c|c|}
\hline \multicolumn{2}{|c|}{ Metafunção ideacional: } \\
\hline Batom vermelho & não é & pra mim \\
\hline Condutor & Processo relacional & Atributo \\
\hline Batom vermelho & Metafunção interpessoal: & pra mim \\
\hline Sujeito & não é & Predicador \\
\hline Modo: declarativo. Deiticidade: presente. Polaridade: positiva. \\
\hline \multicolumn{2}{|c|}{ Metafunção textual } \\
\hline Batom vermelho & não é pra mim \\
\hline Tema & Rema \\
\hline
\end{tabular}

TABELA 1 - Análise da primeira peça publicitária segundo a GSF.

Fonte: Elaboração própria.

Considerando a perspectiva da GDV, analisamos a imagem a partir de seus diferentes aspectos. No que diz respeito ao aspecto ideacional, pudemos identificar o processo reacional. Há um vetor

\footnotetext{
${ }^{2}$ Disponível em: https://www.facebook.com/quemdisseberenicePT/photos/a.210928272644046/311759682560904/?ty pe=1\&theater Acesso em: 10/09/2019. Acesso em: 10/08/2021.

${ }^{3}$ A polaridade poderia ser compreendida a princípio como negativa, porém, o corte do termo "não" altera a polaridade da oração, tornando-a positiva.
} 


\section{REVISTA DA ABRALIN}

formado pela "linha de olhar" da participante (ou reatora) representada, que se direciona para o "não" cortado pelo risco do batom vermelho que está em sua mão. Existe uma triangulação entre o olhar da participante, o "não" cortado (no rumo de seus lábios vermelhos) e o próprio batom. Esses vetores são responsáveis por unir a mensagem, a participante e o produto.

Em relação ao aspecto interpessoal, a distância social pode ser classificada como pessoal próxima, já que a participante é retratada somente até a altura de seus ombros. Seu rosto é retratado em um ângulo de perfil, o que sugere um certo distanciamento entre leitor e imagem. Com relação ao tipo de olhar, trata-se de um olhar de oferta, que também se distancia do leitor.

Quanto ao aspecto composicional, a mensagem posicionada ao lado esquerdo da imagem ("Batom vermelho não é pra mim") é entendida como o dado, ou seja, um elemento já conhecido pelo público. Já a representação da mulher rindo com seu batom vermelho, é o elemento novo apresentado ao consumidor, o que explica por que o termo "não" está riscado por um batom, ressignificando o enunciado.

Discutiremos, a seguir, sobre os processos metonímicos que são construídos nas imagens. O processo acional é relacionado às ações sociais dos participantes. Como mencionado, na imagem, a mulher é representada segurando um batom vermelho, sendo que a palavra "não" é cortada pelo mesmo. A partir dessa representação parcial de um movimento retratado na imagem, podemos identificar a ação tomada anteriormente pela participante: a de cortar o "não", modificando o sentido da frase. A ação representa a quebra de um paradigma relativo ao que é considerado como apropriado ou não para as mulheres. Nesse sentido, o produto representado na imagem, assim como a própria marca que o oferta, podem ser associados com os valores referentes ao empoderamento feminino e ao feminismo, o que atingiria um determinado público de mulheres visado pela marca.

O processo analítico está relacionado à maneira pela qual os participantes são representados, a isso se associa o enquadramento na moldura e os trajes que são tomados como atributos. Como já citado, a participante é representada sob uma distância pessoal próxima, o que reforça o princípio da parcialidade. Ela veste uma blusa branca e justa com decote alto, que quando associada à sua maquiagem gera um certo tom de empoderamento. A representação da participante aproxima-se do real, com modalidade sensorial alta. Entretanto, a frase escrita ao lado esquerdo da imagem possui um degradê de cores que se destacam e se diferenciam do restante da imagem. O degradê é iniciado em um tom azul, uma cor fria, mas após o termo "não" ser cortado de vermelho, uma cor quente, o degradê vai se transformando em amarelo, também quente. A cor vermelha presente no corte do não e também nos lábios da mulher e em seu batom é bastante significativa, por ser associada ao calor, à energia e à saliência (KRESS; VAN LEEUWEN, 2002), o que nos remete à transgressão, à libertação feminina.

O processo classificatório diz respeito à construção identitária das personagens. Na imagem em questão, a participante representa uma mulher empoderada, que quebra com os paradigmas relacionados à construção do feminino, mais especificamente no que concerne aos produtos de maquiagem. A representação da personagem busca criar o efeito de que ela é uma mulher que define sua própria identidade. Tal identidade é representada metonimicamente através dos processos já analisados, e é possível identificarmos uma metonímia de ação por atributo (FENG, 2017). 


\section{REVISTA DA ABRALIN}

O processo reacional relaciona-se às emoções que podem ser representadas visualmente ou despertadas no leitor, a isso associam-se as estratégias interacionais utilizadas. Na imagem, a participante é representada sorrindo em direção à frase cortada por seu batom, o que denota confiança/segurança. Podemos identificar a metonímia da reação por emoção (FENG, 2017). A emoção construída metonimicamente corrobora a imagem de mulher que a marca busca representar. Além disso, sua representação pode provocar empatia no leitor, que poderá se identificar com a imagem e desejar adquirir o produto ofertado.

\subsection{Peça publicitária da marca Avon}

A segunda peça publicitária examinada faz parte da campanha "O que te define" veiculada pela marca Avon. A campanha é protagonizada pelas cantoras Karol Conka, MC Carol e LAY. No vídeo da campanha, a MC Carol, representada na peça publicitária reproduzida abaixo, é a responsável pela seguinte fala ${ }^{4}$ : "Um olhar confiante, na voz a atitude, vou mostrar que ser negra e gorda é virtude. Levanta sua cabeça, você não pode parar. O que te define é o seu olhar" - mensagem reforçada pela imagem.

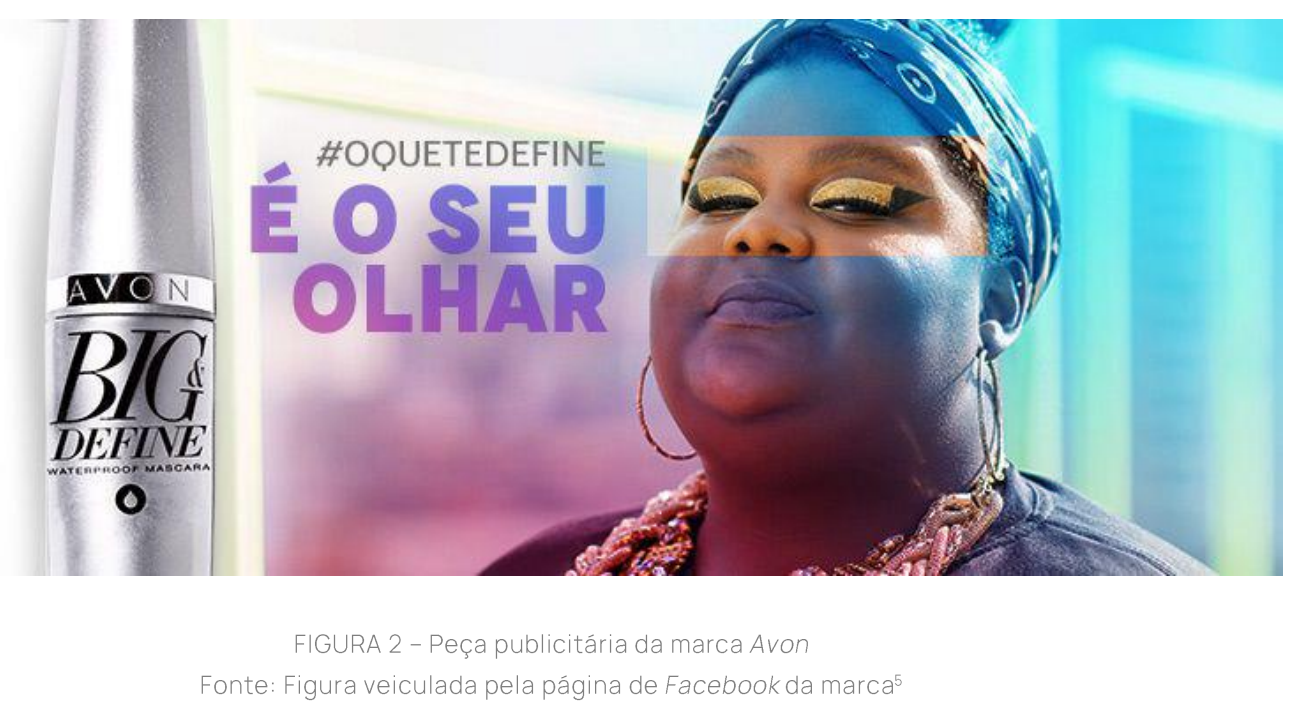

Seguindo os pressupostos da GSF, analisamos os dizeres da peça conforme as três metafunções já mencionadas. Optamos por manter a expressão "o que te define" como um "bloco", considerando que na frase "\#oquetedefine é o seu olhar", o uso da hashtag, que circula nas mídias sociais, reforça um destaque dado à expressão. Com isso, chegamos às seguintes conclusões:

\footnotetext{
${ }^{4}$ Disponivel em: https://www.youtube.com/watch?v=GF5bJ6eafGo\&feature=youtu.be. Acesso em: $10 / 08 / 2021$.

${ }^{5}$ Disponível em: https://www.facebook.com/avonbr/photos/a.10150682041816195/10154140264691195/?type=3\&theat er. Acesso em: 10/08/2021.
} 


\section{REVISTA DA ABRALIN}

\begin{tabular}{|c|c|c|}
\hline \multicolumn{3}{|c|}{ Metafunção Ideacional: } \\
\hline \#oquetedefine & é & o seu olhar \\
\hline Condutor & Processo relacional & Atributo \\
\hline \multicolumn{3}{|c|}{ Metafunção Interpessoal: } \\
\hline \#oquetedefine & é & P seu olhar \\
\hline Sujeito & Finito & \\
\hline Modo: declarativo. Deiticidade: presente. Polaridade: positiva. \\
\hline \multicolumn{2}{|c|}{ Metafunção Textual } \\
\hline \#oquetedefine & \multicolumn{2}{c|}{ Rema olhar } \\
\hline Tema & \multicolumn{2}{c|}{} \\
\hline
\end{tabular}

TABELA 2 - Análise da segunda peça publicitária segundo a GSF.

Fonte: Elaboração própria.

Sob o ponto de vista da GDV, observamos que, quanto ao aspecto ideacional da peça, podemos identificar o processo simbólico. A condutora é representada pela Mc Carol, cuja identidade é associada ao produto divulgado, o atributo simbólico, representado pela máscara de cílios BigDefine salientada na imagem.

Em relação ao aspecto interpessoal, a distância social pode ser classificada como pessoal próxima (quase intimidade, já que apenas uma pequena parte de seus ombros é retratada). O rosto é retratado sob um ângulo baixo, o que indica um poder da imagem sobre o leitor. Com relação ao tipo de olhar, trata-se de um olhar de demanda/sedução: a participante olha para o leitor do alto e sorri, invocando uma atitude daquele que observa a imagem.

No que diz respeito ao aspecto composicional, a representação do produto junto à mensagem posicionada ao lado esquerdo da imagem ("\#oquetedefine é o seu olhar") é entendida como o dado, elemento já conhecido pelo público. Já a representação da Mc Carol com um destaque a seus olhos maquiados e ao seu olhar que se direciona diretamente ao leitor, é o elemento novo apresentado ao consumidor. Há uma saliência tanto na representação da máscara de cílios quanto no enquadramento do olhar da participante.

Tudo isso nos leva ao exame dos processos metonímicos que podem ser identificados na peça em questão. No que concerne ao processo analítico, observa-se que o modo como a participante é retratada (distância social entre pessoal próxima e intimidade) reforça o princípio da parcialidade, em que as partes são mostradas no lugar do todo, tendo em vista que o foco da imagem está no rosto da MC Carol, especialmente em seus olhos. Os acessórios utilizados pela participante contribuem para a construção de sua posição de empoderamento. Dentro do retângulo que enquadra os olhos e nariz da participante, as cores aproximam-se do real, e há um destaque para a maquiagem usada na participante, tendo em vista que se trata do anúncio de um produto de beleza. Entretanto, no restante da imagem, a modalidade sensorial é baixa, já que o uso das tonalidades roxa e azul sobrepõe a fotografia. Essa estratégia é utilizada para garantir o foco no enquadramento do olhar da participante, o que é significativo na imagem, uma vez que o slogan da campanha é "\#oquetedefine é o seu olhar".

Em relação ao processo classificatório, na imagem, a MC Carol representa uma mulher empoderada, que quebra os padrões pré-estabelecidos de beleza, por se tratar de uma mulher negra e gorda. Há uma relação de sinonímia entre o que é dito no vídeo da campanha e o que é representado na 


\section{REVISTA DA ABRALIN}

imagem, no que diz respeito à identidade da personagem. A presença de uma mulher negra e gorda como protagonista de uma campanha de produtos de beleza pode ser considerada como uma fuga de estereótipos, o que poderia acarretar a aceitação dos produtos por um novo tipo de público. Desse modo, podemos identificar a presença da metonímia de membro de uma categoria por toda a categoria (FENG, 2017).

Quanto ao processo reacional, observa-se que o olhar e sorriso confiante da participante, que olha diretamente para o leitor, é fundamental para a construção da emoção na imagem. O seu olhar de demanda evoca uma atitude do leitor tanto no que diz respeito à representação da mulher na publicidade quanto ao próprio posicionamento das mulheres na sociedade. Podemos identificar, novamente, a presença de uma metonímia de reação por emoção.

\subsection{Peça publicitária da marca Dove}

A terceira peça publicitária analisada faz parte da campanha "Beleza fora da caixa" promovida pela marca Dove. Nessa campanha, a marca produz uma série de cartazes que possuem caixas de textos sugerindo que o leitor imagine um determinado tipo de mulher, enquanto as mulheres representadas nas imagens, apesar de possuírem as características descritas, fogem dos padrões de beleza préestabelecidos. As caixas servem para ativar o conhecimento prévio do leitor em relação ao tema, e a representação das mulheres reais e desconhecidas pelo público, gera uma quebra de expectativa. A imagem reproduzida abaixo é uma das peças que afirmam que "existe beleza fora da caixa": 


\section{REVISTA DA ABRALIN}

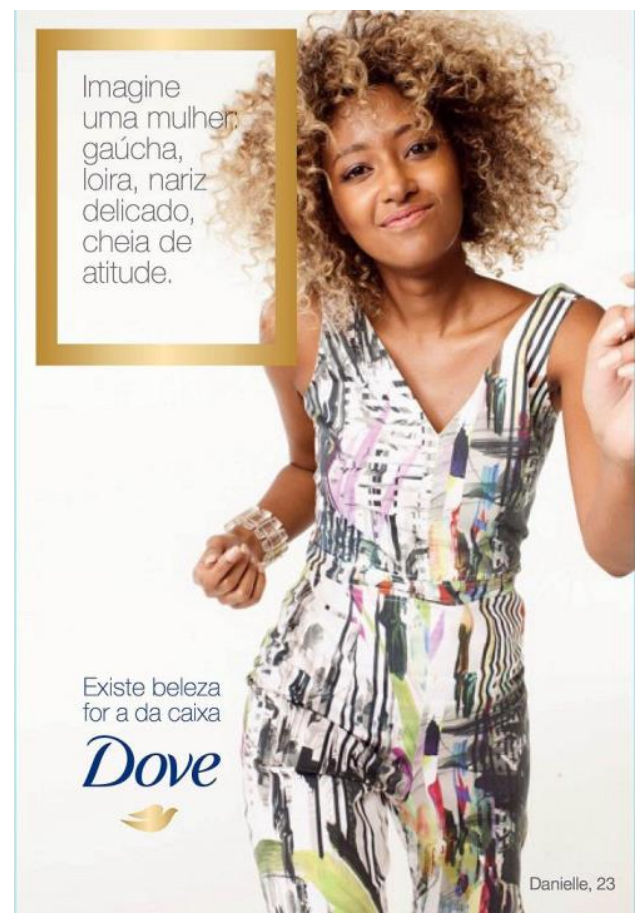

FIGURA 3 - Peça publicitária da marca Dove

Fonte: Figura veiculada pela página de Facebook da marca ${ }^{6}$

Considerando os pressupostos da GSF, o exame relativo às metafunções se deu da seguinte forma:

\begin{tabular}{|c|c|c|}
\hline \multicolumn{2}{|c|}{ Metafunção Ideacional: } \\
\hline [você oculto] & Imagine & uma mulher (...) \\
\hline Experenciador oculto & Processo mental & Imagine \\
\hline \multicolumn{2}{|c|}{ Metafunção Interpessoal: } \\
\hline Imagine & uma mulher (...) & Predicador \\
\hline Predicador & Complemento \\
\hline Modo: imperativo. Deiticidade: presente. Polaridade: positiva. & $(\ldots)$ \\
\hline \multicolumn{2}{|c|}{ Metafunção Textual } \\
\hline $\begin{array}{c}\text { Imagine uma mulher gaúcha, loira, nariz delicado, } \\
\text { cheia de atitude }\end{array}$ & Rema \\
\hline \multicolumn{2}{|c|}{ Tema } & \\
\hline
\end{tabular}

TABELA 3 - Análise da terceira peça publicitária segundo a GSF.

Fonte: Elaboração própria.

Nesse caso, optamos por identificar o tema e o rema de acordo com o que é apresentado como dado (todo o texto) e novo (representação da mulher) na imagem, considerando que se trata de um

\footnotetext{
${ }^{6}$ Disponível em:

https://www.facebook.com/DoveBr/photos/a.285230738269681/933058723486876/?type=3\&theater. Acesso em: 10/08/2021.
} 


\section{REVISTA DA ABRALIN}

texto multimodal, em que a imagem da mulher representada é fundamental para a compreensão do todo. Na parte de baixo da imagem, podemos observar a presença de outra frase, o slogan da campanha: "Existe beleza fora da caixa". Analisando-o, chegamos às seguintes conclusões:

\begin{tabular}{|c|c|}
\hline \multicolumn{3}{|c|}{ Metafunção Ideacional: } \\
\hline Existe & beleza fora da caixa \\
\hline Processo existencial & Existente \\
\hline Existe & Metafunção Interpessoal: \\
\hline Finito + Predicador & beleza fora da caixa \\
\hline Modo: declarativo. Deiticidade: presente. Polaridade: positiva. & Complemento \\
\hline \multicolumn{2}{|c|}{ Metafunção Textual } \\
\hline Existe beleza & fora da caixa \\
\hline Tema & Rema \\
\hline
\end{tabular}

TABELA 4 - Análise da terceira peça publicitária segundo a GSF - parte 2

Fonte: Elaboração própria.

Já em relação às categorias da GDV, pudemos identificar, sob o aspecto ideacional, o processo de ação, uma vez que o ator seria a mulher representada dançando. No que concerne ao aspecto interpessoal, observa-se que a distância social pode ser identificada como pessoal distante, já que a participante é representa até a altura um pouco abaixo do quadril. Ela é retratada sob um ângulo baixo, o que indica um poder da imagem sobre o leitor. Com relação ao tipo de olhar, trata-se de um olhar de demanda: a participante olha diretamente para o leitor.

No que diz respeito ao aspecto composicional, a mensagem posicionada ao lado esquerdo da imagem dentro de um quadro ("Imagine uma mulher gaúcha, loira, nariz delicado, cheia de atitude") é entendida como o dado. A representação da mulher, que de fato possui as características mencionadas, porém não da forma esperada - já que se trata de uma mulher negra e não de uma mulher branca que normalmente estamparia essa descrição - é o elemento novo apresentado ao consumidor. Há, nesse caso, uma quebra de expectativa que vem da leitura racista de como é a imagem de uma mulher bela. A parte de cima da imagem, onde estão posicionadas essa frase e o rosto da mulher, trata-se do elemento ideal. Quanto à parte de baixo, onde encontra-se a ancoragem da representação da marca Dove, junto ao slogan da campanha ("Existe beleza fora da caixa"), é o elemento real.

Passando aos processos metonímicos, observa-se que, em relação ao processo acional, na imagem, a participante é representada em movimento, dançando, "cheia de atitude" (conforme escrito na caixa). Essa representação parcial ativa o conhecimento prévio do leitor acerca de tal movimento. A ação da personagem representa o recurso principal para construir sua atitude, desse modo, podemos identificar a presença de uma metonímia de ação por atributo (FENG, 2017).

Sobre o processo analítico, como já mencionado, a participante é representada sob uma distância pessoal distante, reforçando mais uma vez o princípio da parcialidade. O seu vestido, com uma estampa moderna, corrobora para a representação de uma mulher "cheia de atitude". A imagem, no que diz respeito à figura da mulher, aproxima-se do real e possui modalidade sensorial alta. $\mathrm{O}$ fundo branco contribui para que o foco da imagem esteja na figura da participante. 


\section{REVISTA DA ABRALIN}

No que concerne ao processo classificatório, a construção identitária da personagem configura o ponto central da imagem. Na caixa de texto, é solicitado ao leitor que imagine uma mulher gaúcha, loira e de nariz delicado. Essas características, que são normalmente associadas às mulheres brancas, são representadas por uma mulher negra. Ao quebrar padrões pré-estabelecidos e promover o reconhecimento da beleza em diferentes tipos de mulher, a marca pode gerar uma adesão por diferentes públicos de mulheres. Podemos identificar, novamente, a presença da metonímia de membro de uma categoria por toda a categoria (FENG, 2017).

Quanto ao processo reacional, o sorriso e a expressão facial da mulher representada na imagem denotam confiança/segurança, o que reforça o propósito da marca de valorizar os diferentes tipos de beleza, a fim de aumentar a autoestima e confiança de outras mulheres. Esse tipo de representação pode fortalecer a demanda social de modificações no que diz respeito à representação feminina de um modo geral, e mais especificamente no campo dos produtos cosméticos. A representação da emoção pode gerar empatia no público-alvo e contribuir para a adesão à marca. Podemos identificar, portanto, a metonímia de reação por emoção (FENG, 2017).

\section{Considerações finais}

A partir da análise das três peças publicitárias, podemos observar que as imagens representam uma quebra de hegemonia no que diz respeito à representação das mulheres em publicidades. Os aspectos ideológicos presentes na primeira imagem associam-se aos valores feministas, tendo em vista a construção da campanha que colocou em foco a discussão sobre o papel da mulher na sociedade. No vídeo da campanha, as mulheres aparecem cortando os "nãos" que as restringem, em frases como "ser chefe não é pra mim", "comprar camisinha não é pra mim". Assim, é importante observamos que em vez de somente omitir o não e dizer que "batom vermelho é pra mim", a campanha publicitária optou por representar as mulheres como as responsáveis pelo corte do não, ou seja, como as responsáveis pela desconstrução dessa visão que circula na sociedade.

Já nas outras peças publicitárias analisadas, o protagonismo de mulheres negras, e uma delas sendo gorda, quebra com os estereótipos relacionados às mulheres que são representadas em campanhas de produtos de beleza. Na segunda imagem, a tentativa de "mostrar que ser negra e gorda é virtude", vai contra às ideologias racista e gordofóbica estabelecidas na sociedade. Na terceira peça, o protagonismo de uma mulher negra, que é também loira e gaúcha, faz com que a construção da imagem passe do imaginário estereotipado para a representação real da mulher. Assim, podemos notar que as campanhas analisadas possuem aspectos ideológicos direcionados diretamente ao empoderamento feminino.

Diante do exposto, podemos afirmar que as marcas quem disse berenice?, Avon e Dove modulam os textos multimodais de suas peças publicitárias a fim de convencer o público-alvo de seu posicionamento engajado e comprometido com as atuais demandas sociais com relação à representação da 


\section{REVISTA DA ABRALIN}

mulher. Portanto, filiando-se ao movimento FemVertising, as marcas visam persuadir diferentes grupos de mulheres a fim de se beneficiar comercialmente.

Com a análise, tentamos mostrar de que maneira os processos metonímicos se inscrevem nas imagens como uma estratégia persuasiva. Pudemos perceber que as representações das participantes e de suas emoções estão ligadas a atuais normas e valores sociais. Assim, ao promover a identificação de um determinado público com tais convicções, este fica suscetível a experienciar determinadas emoções, levando-o à adesão ao que é proposto pelas marcas.

Este trabalho buscou apresentar uma reflexão acerca do posicionamento da publicidade diante do ressurgimento de movimentos contestatórios de cunho feminista, lançando luz sobre o estudo das estratégias persuasivas na publicidade contemporânea, evidenciando seus modos de orientar e reforçar determinados pontos de vista a partir de objetivos mercadológicos.

\section{REFERÊNCIAS}

AZEVEDO, Jade Vilar de. Feminismo de revista: Análise da apropriação do movimento feminista pelo mercado a partir da revista Elle. Trabalho de Conclusão de Curso (Jornalismo). Universidade Federal da Paraíba. João Pessoa: 2017. 125p.

FAIRCLOUGH, N. Discurso e mudança social. Brasília: Universidade de Brasília, 2001.

FENG, W. D. Metonymy and visual representation: towards a social semiotic framework of visual metonymy. Visual Communication, v. 16, n. 4, p. 441-466, 2017.

HALLIDAY, M. A. K. An introduction to functional grammar. London: Edward Arnold, 1994.

HALLIDAY, M. A. K.; MATTHIESSEN, C. M. I. M. An introduction to functional grammar. 3.ed. London: Arnold, 2004.

KRESS, G.; VAN LEEUWEN, T. Reading images: the grammar of visual design. London: Routledge, 1996.

KRESS, G.; VAN LEEUWEN, T. Colour as a semiotic mode: notes for a grammar of colour. Visual Communication, v. 1, n. 3, p. 343-368, 2002.

SOARES. L. A. Análise do jornal popular Super Notícia sob enfoque crítico e multimodal. Revista Alfa, São Paulo, v. 61, n.3, p.575-597, 2017. 